$16^{\text {th }}$ INTERNATIONAL MULTIDISCIPLINARY SCIENTIFIC GEOCONFERENCE SGEM 2016

Book 2 Informatics, Geoinformatics and Remote Sensing CONFERENCE PROCEEDINGS Volume I

INFORMATICS GEOINFORMATICS 


\section{$16^{\text {th }}$ INTERNATIONAL MULTIDISCIPLINARY SCIENTIFIC GEOCONFERENCE S G E M 2016}

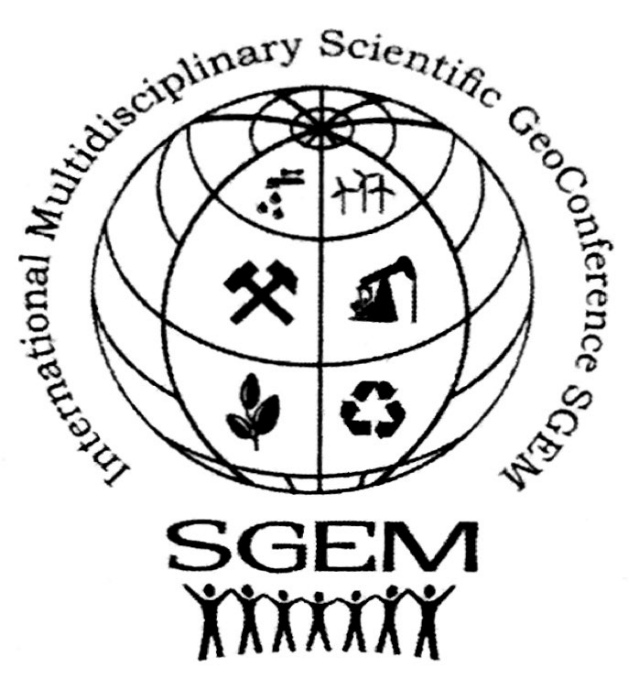

INFORMATICS, GEOINFORMATICS AND REMOTE SENSING CONFERENCE PROCEEDINGS

VOLUME I

\section{INFORMATICS}

GEOINFORMATICS

30 June - 6 July, 2016 Albena, Bulgaria 


\section{DISCLAIMER}

This book contains abstracts and complete papers approved by the Conference Review Committee. Authors are responsible for the content and accuracy.

Opinions expressed may not necessarily reflect the position of the International Scientific Council of SGEM.

Information in the SGEM 2016 Conference Proceedings is subject to change without notice. No part of this book may be reproduced or transmitted in any form or by any means, electronic or mechanical, for any purpose, without the express written permission of the International Scientific Council of SGEM.

Copyright (C) SGEM2016

All Rights Reserved by the International Multidisciplinary Scientific GeoConferences SGEM Published by STEF92 Technology Ltd., 51 “Alexander Malinov” Blvd., 1712 Sofia, Bulgaria Total print: 5000

ISBN 978-619-7105-58-2

ISSN 1314-2704

DOI: $10.5593 /$ sgem2016B21

INTERNATIONAL MULTIDISCIPLINARY SCIENTIFIC GEOCONFERENCE SGEM Secretariat Bureau

Phone: $\quad+35924051841$

Fax: $\quad+35924051865$

E-mails: sgem@sgem.org | sgem@stef92.com

URL: www.sgem.org 
- PROF. PETER REINARTZ, GERMANY

- PROF. DR. JÓzSEF ÁdAM, HUNGARY

- prof. RUi miguel marques moUra, portugal

- PROF. DR. ING. KAREL PAVELKA, CZECH REPUBLIC

- prof. DR. MARCEL MOJZES, SLOVAKIA

- ASSOC. PROF. DR MILAN hOREMUZ, SWEDEN

- dR. Tiberiu RUS, Romania

- DR. MARKO KREVS, SLOVENIA 


\section{CONFERENCE PROCEEDINGS CONTENTS}

\section{INFORMATICS}

1. A NEW MODEL FOR ESTIMATING THE RISK OF BANKRUPTCY OF THE INSURANCE COMPANIES BASED ON THE ARTIFICIAL NEURAL NETWORKS, Lect. Doru Constantin, As.Prof. Emilia Clipici, University of Pitesti, Romania. 3

2. THE ANALYSIS OF CHARACTERISTICS OF PRIORITY MODEL OF THE SERVER IN A DISTRIBUTED INFORMATION SYSTEM, MuravyevaVitkovskaya L.A., Kalinin I.V. , University ITMO, Russia.

3. ANALYSIS OF STUDENT'S BEHAVIOR IN LMS ELOGIKA, MSc. Marek Mensik, Ph.D., MSc. Pavla Drazdilova, Ph.D., VSB-Technical University of Ostrava, Czech Republic

4. ANALYSIS OF THE IMPACT OF USING HIGH PERFORMANCE COMPUTING IN FIRE MODELING, PhD. Std. Eng. Marius Cornel Suvar, $\mathrm{PhD}$.Std.Eng. Nicolae Ioan Vlasin, PhD.Eng. Vlad Mihai Pasculescu, PhD.Eng. Emilian Ghicioi, National Institute for Research and Development in Mine Safety and Protection to Explosion - INSEMEX, Romania .... .25

5. ANALYSIS OF THE POTENTIAL OF CROSS-PLATFORM MOBILE APPLICATIONS AS DATA MANAGEMENT TOOLS IN MEDICAL PURPOSES, M.Sc. Dalibor Serafimovski, Prof. Dr. Aleksandar Krstev, Prof. Dr. Kosta Mitreski, University Goce Delcev, FYR of Macedonia

6. ANALYSIS OF THE PROPOSED SEMANTIC APPROACH TO DESIGN OF INFORMATION SYSTEM INTERFACE, Assist. Prof. Svetlana Belikova, Prof. Dr. Yury Rogozov, Assoc. Prof. Dr. Alexander Sviridov, Southern Federal University, Russia

7. APPLICATION OF INFORMATION TECHNOLOGIES IN MANAGEMENT OF GREENHOUSE GASES AND WASTES, Assoc.Prof.DSc Marina Medvedeva, Assoc.Prof.DSc Silvia Parusheva, Ural Federal University, Russia

8. APPLICATION OF TECNOMATIX PLANT SIMULATION IN ANALYZING THE POSSIBILITIES FOR RAPID EXIT TAXIWAY, Ing. Michal Hovanec, PhD. , Ing. Peter Korba, PhD., Ing. Jana Cibereova, assoc. prof. Ing. Jan Pila, PhD., Ing. Oskar Sloboda, Technical University of Kosice, Slovakia.

9. APPLYING SIMULATION MODELS WHILE FORECASTING THE DEVELOPMENT OF SHOCK CONDITIONS, Assos.Prof. Dr. Svetlana Lapshina, Elena Nozhina, Ural Federal University, Russia 


\section{SECTION INFORMATICS}




\title{
ANALYSIS OF THE POTENTIAL OF CROSS-PLATFORM MOBILE APPLICATIONS AS DATA MANAGEMENT TOOLS IN MEDICAL PURPOSES
}

\author{
M. Sc. Dalibor Serafimovski ${ }^{1}$ \\ Prof. Dr. Aleksandar Krstev ${ }^{1}$ \\ Full Prof. Dr. Kosta Mitreski ${ }^{2}$ \\ ${ }^{1}$ Faculty of Computer Science, University "Goce Delčev"-Štip, R. Macedonia \\ ${ }^{2}$ Faculty of Computer Science and Engineering, University "Ss.Cyril and Methodius" Skopje, R. \\ Macedonia
}

\begin{abstract}
The potential of the mobile devices raised a lot in the past few years. Today the mobile devices are maybe the most important target for developers around the world. The companies around the world are trying to increase their efficiency by implementing mobile based tools and applications for better and faster working. Current researches and surveys are showing that people are more likely to use mobile devices for everyday tasks then PC's or laptops. This global phenomenon is also reflecting the medical world. Currently, many medical research centers and hospitals in the world are investigating the potential of the mobile based technology and trying to implement the best working model that fits their needs. Also, some medical robotic devices that were attractive only two or three years ago, today are being replaced by mobile phones and smart watches just because they are easier for using, more convenient and also they are offering lots of possibilities. In this paper we are focused on analyzing purposed cross-platform models for data handling in medical purposes. The paper covers the techniques and models for medical data exchange in every level using cross-platform technologies and smart devices.
\end{abstract}

Key words: mobile, medical, data, smart, cross-platform, applications, exchange

\section{INTRODUCTION}

Collecting data is becoming essential in the daily operations at every level in all branches of everyday living. In the field of industry, medicine, the work of the government institutions in the field of security, marketing literally everywhere there is a need for rapid exchange of large amounts of data which is directly related to the successful operation of any of the above mentioned branches. The exchange of data in daily operations more recently becomes a process that slowly but surely begins to completely depend on mobile platforms. The level of communication is reduced mostly on fast data exchange using a mobile phone from one user or group of users connected to a network or a central source of information such as a central database that is fed with information from a vast number of mobile users on the ground that usually send information on the go. The exchange of information using a mobile phone exceeds the expectations of many of the companies that deal with production of mobile smart devices and mobile applications worldwide. 
One of the branches which undoubtedly occupies a very important place in everyday human living is the medicine. In the world currently there are multiple ways to communicate and exchange data for medicinal purposes. Rapid and accurate exchange of important medical data is considered crucial in the process of detection, prevention or treatment of a particular disease. There are many campaigns that stretch currently in the world for prevention of certain incurable diseases such as malignant diseases. The new era of access to information in the form of mobile applications opens the way to mobile platforms for their serious implementation as handy tools that can be used in medicinal purposes. [2] The main purpose of this paper is to present several cross-platform models that would be effective in the process of management of information in medical purposes and would be easy to use in clinical practice.

Some technologies which are being used for exchange of information in medical purposes are standardized and generally accepted, while some technologies are still considered non-standard. [6] The use of cross-platform models of mobile systems and technologies can be considered arbitrary and it is strongly recommended these technologies to be used as tools that may informally contribute to the exchange of data in medical purposes. Many of the campaigns to prevent certain serious diseases in the world are run by actively sending SMS messages to certain previously targeted group of users. [8] The use of the social networks with the help of the smart mobile devices simplified this process by making it possible to lead free campaigns on social networks through timely announcements direct to consumers in the form of notifications directly to their smart devices.

The whole scientific world agrees that the use of smart mobile devices in medical purposes is the future. The analysis of the electronic stores for mobile applications described in some scientific papers are showing that the number of mobile medical applications since 2014 was nearly 100,000 (one hundred thousand applications). Some authors even go so far as to say that in the future can be expected for each disease to be prescribed a corresponding smart application, the same as a prescribed medicine. Although the potential of smart mobile tools is undoubtedly very great, yet these technologies are still at the level of commercial products available on the market. Medical institutions are lagging greatly in this area primarily because these technologies are still in the experimental stage and the developers are working on increasing security in the use of mobile applications in medical purposes primarily because the most important thing in this process is the health of the patient to be fully protected. $[9,10]$

If we analyze the available literature in this area it will be noted that still there are not available standardized guidelines and procedures that indicate the main parts of which certain eHealth or mHealth mobile health application should be made to be fully compatible for use. [5] Several research teams in the world including many medical professionals are trying to publish scientific studies backed up by clinical trials which will give some guidance to the manufacturers of these type of applications to stick on in the future. In this paper we present several models for multiplatform informal sharing of data for medical purposes which we believe may be effective for patients and it also may affect in reducing the cost of health care and help in the timely detection and prevention of serious diseases. [7] 


\section{PROPOSED MODEL: SOCIAL NETWORKS INTEGRATION}

Social networks are definitely one of the most used things on the Internet especially among young people. Also using social networks through mobile devices is currently the most accepted way of using social networks mostly because of the practical opportunity to share updates on the go. This represents an excellent opportunity for researchers in eHealth and mHealth areas to use this trend to create entirely free campaigns to prevent certain diseases and thus collect a large amount of data that later would be used for production of medical scientific studies. This model has been tested by several groups of students from our universities. [3] The model includes an active user registration through their personal accounts on social networks Facebook and Twitter. The use of social networks as tools for registration of user groups currently is the most acceptable way for all developers of software systems as a practical alternative instead of creating standard user accounts for each application separately.

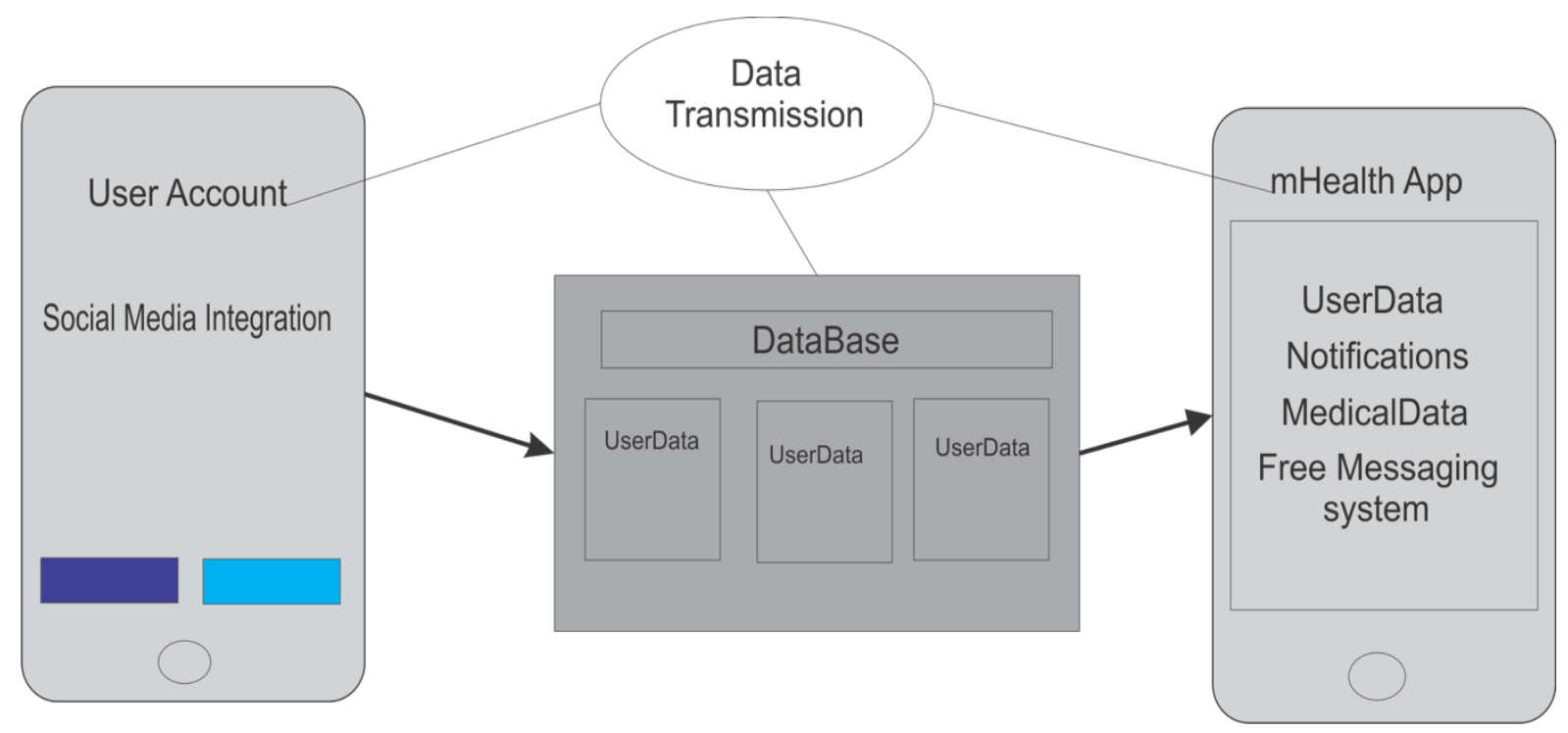

Fig.1 Visual illustration of the social networks integration proposed model

During the process of testing, we conducted registration of more than 200 users in a central database that has registered in our database using their accounts on social networks Facebook and Twitter. Previously a separate user authentication module was made based on API documentation and developer tools offered by both social platforms. The module is fully integrated into mHealth test application that was developed for the purposes of this research. This proposed model fully guarantees the safety of the users of the application because the authentication of users is done by a third party. This avoids the potential possibility of creating false accounts and bots. Once the user is registered, the application through appropriate data service captures data about the user and saves it into SQLite central database. The database further is connected to special module for sending notifications and free messages to the users of the application. This proposed model is suitable for organizing online campaigns to raise awareness about the risk of a certain disease completely free of charge simply by targeting a large group of people through social networks. 


\section{Example code: Facebook integration}

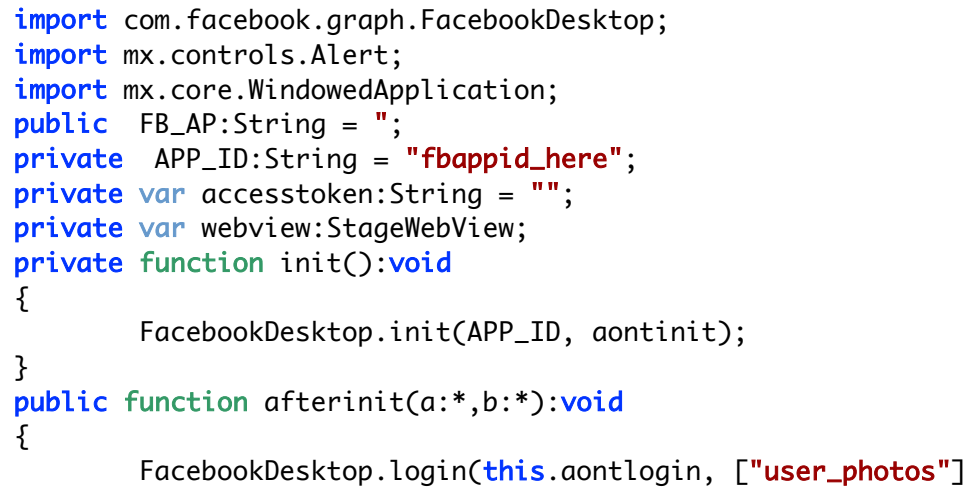

The advantage of this approach is that mobile applications of this type are completely independent from the operating system or device on which they are executed and that is making them especially suitable for use and reduces costs.

\section{Results}

Above we mentioned that the experiment that was conducted was attended by more than 200 students with their user profiles. With the help of mHealth test application, several times a day we were sending messages and other notifications directly to the mobile phones of all registered users. Finally, an online survey was conducted to test and check how many users are dissatisfied with this way of data exchange in medical purposes and also to check the level of effectiveness. More than $90 \%$ of surveyed participants in this practical experiment responded that they had a positive experience with this kind of direct communication in medicinal purposes, $99 \%$ of those involved in the trial have said that this model is completely acceptable, convenient and easy to use. Over $80 \%$ of those involved in the experiment said they had absolutely no technical problem in using the app on different devices with different hardware potential.

\section{PROPOSED MODEL: GEOLOCATION AND MAPPING}

At the moment there is an undefined tendency in the world that is leading to a complete transfer of all information and communication services at the level of mobile platforms. The world goes mobile. As mentioned above, research shows that people much better deal with mobile devices and the process of transferring data using mobile devices it's far simpler and faster as opposed to the standard operation of the computer. One of the important features of smart mobile devices is their ability to detect the current geographic location. All smart devices today offer this option. Already many years by means of detecting the geographical location and with the help of sophisticated applications for mobile devices that offer detailed maps, this technology facilitates the movement and navigation of people from one point to another in any part of the planet earth. 
Taking this into consideration, we decided to test a prototype model which will include working with geographic location and mapping. The proposed model consists of a module called GeoData built into mHealth test application developed for the purposes of this research. The module monitors the pollution of the city of Skopje by gathering information from the meters in town. The module is directly connected to another module in the application which contains information about possible diseases of the user who is currently using mHealth test application.

To monitor the geographical location by the application, the user needs to grant permission and agree it's location to be monitored by the application. When the user finds himself in the zone where currently is registered increased pollution, the application connects to the database that keeps information about his health and calculates the risk of staying in that area at that point. [2] The information is forwarded in the form of a notification to the mobile device of the user. Additionally, the database keeps data on the total duration of stay in the environment in which high contamination is measured within 24 hours. The application contains a map in which are marked all the medical facilities nearby, divided by the distance from the current location.

\section{Results}

Using the built-in functionality in this module, we conducted an informal test of pollution in different environments. The tests included 300 test users from different cities who voluntarily signed up to the application with their own user profiles. By monitoring their geographical location in various environments and comparing the data with the monitoring stations, we received informal results of exposure to air pollution during 24 hours in different areas. These results are not $100 \%$ accurate and do not represent a relevant sample, the main objective was to demonstrate the potential of this model for use in future research and informal work with data of this type in medical purposes. The results of the month-long collection of data from the application are presented in the following graph.

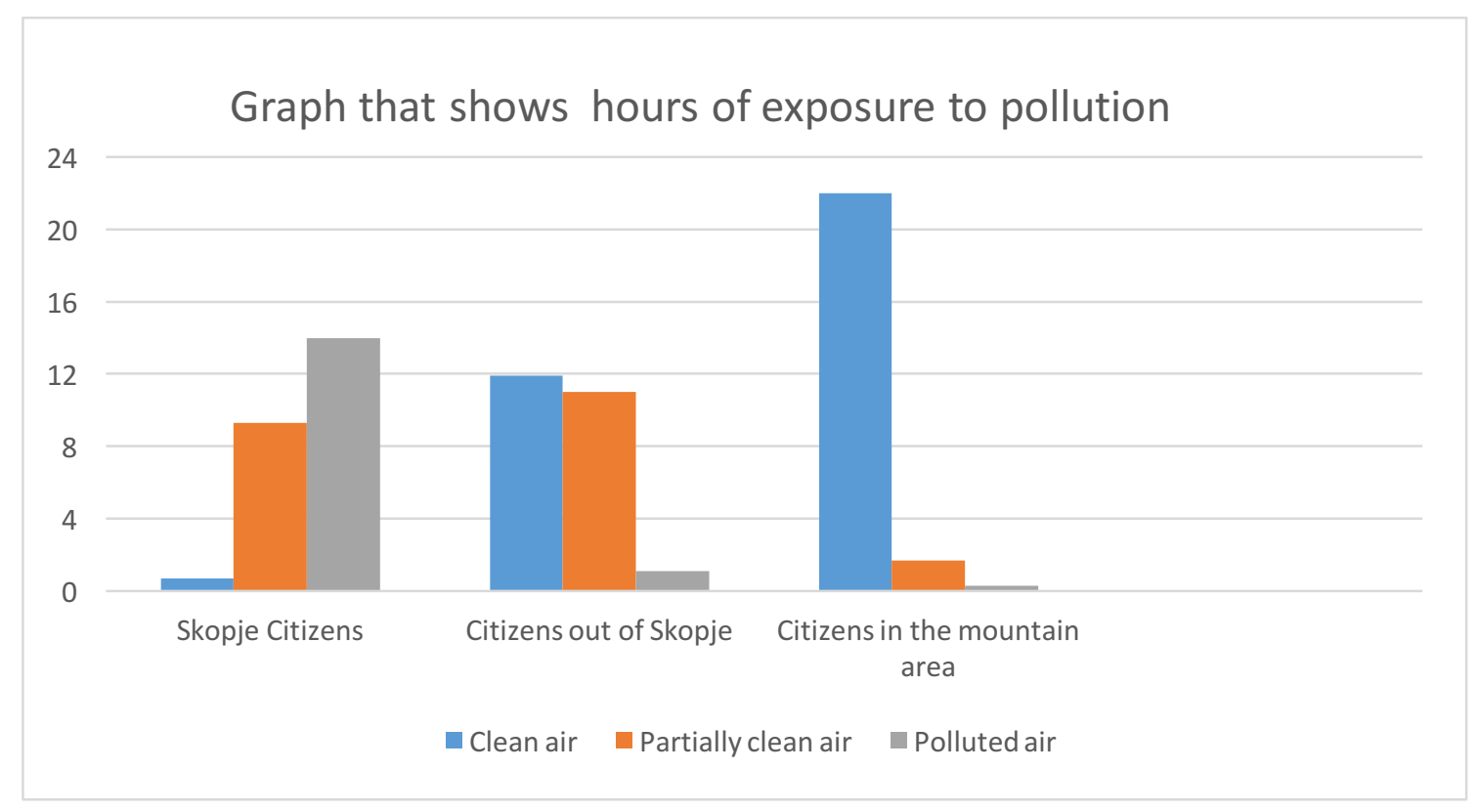




\section{PORPOSED MODEL: CAMERA SCANNING}

This model is perhaps one of the most interesting and creative models with great potential in research. We know that every year with the release of each new model of smart mobile devices, increases the hardware potential of the device. The built-in Camera inside the mobile devices is perhaps one of the most important pieces of hardware which is maximally used especially among the younger population. We have tried to analyze the possibility of implementing cross-platform model that would be totally independent from the platform and the hardware potential of the device on which it performs and which in its basic structure will include data processing in the form of images that can be used for medical purposes.[4] There are many current research projects in the world that are related to artificial intelligence and are based on the recognition of certain diseases through computer analysis of images. Some of these studies already published results that are encouraging. For the purposes of this research we have developed a prototype module whose cross-platform functionality was tested on Android mobile and tablet devices, iOS mobile and tablet devices and BlackBerry PlayBook tablet. The module has shown excellent results in testing of the functionality in all devices equally which basically gives the chance for potential market penetration and its commercial exploitation.

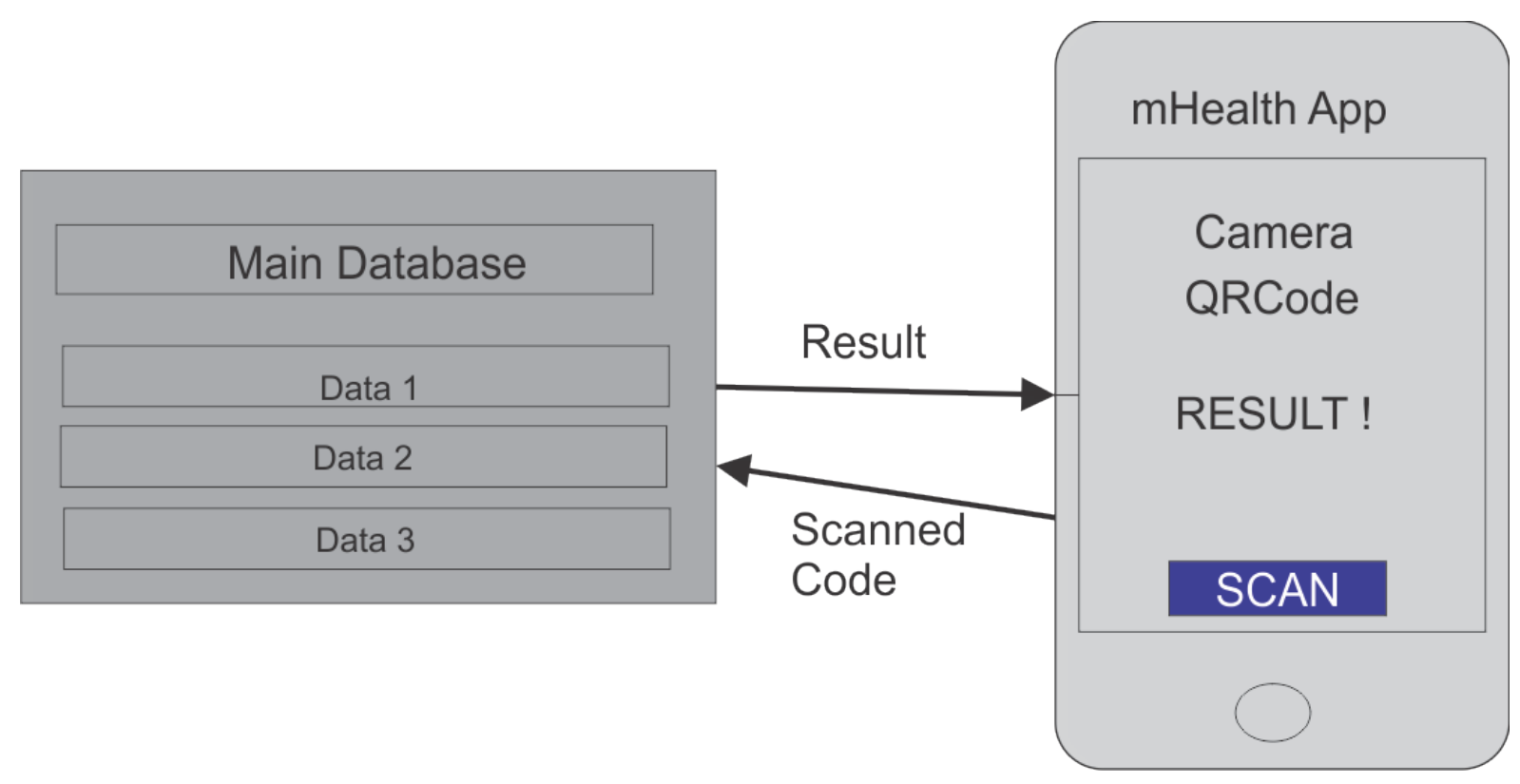

Fig.2 Concept of the purposed camera model

\section{Results}

Within this part of the research a simple experiment was performed to test the potential of the proposed model. Different medical devices mostly drugs were labeled with pre-generated QR codes. All the codes used for marking of the medications and the medical devices were previously stored in the database. Inside the CameraScn module which is part of mHealth test application was built a QR code recognition system that uses the built-in camera in all iOS and Android smart devices. 
In the experiment attended by three groups of students aimed to investigate the credibility of a particular drug or medical device by scanning the code mobile device. After a successful scan code for a period of 1.5 to 3 seconds in iOS devices and 2 to 4 seconds in Android devices, the app gives feedback whether the scanned code exists or does not exist in the database. For those medical devices or drugs that are previously registered in our test database, the application returns a positive result, while for those who are not registered, the application returns a negative result.

This concept in the future may be realistically implemented in actual operation. The concept is inexpensive, easy to use and quite fast. The most important thing is that the technology is cross-platform oriented and do not depend on the user's device or installed operating system. This experiment was conducted in a student laboratory in order to test the effectiveness of the proposed model. It is necessary in the future to conduct further research and perhaps to change the legislation to practically implement this model in medical purposes. [1] We believe that using this concept in the field may lead to removal from the market of many false medical devices and drugs and thus directly increase patient safety. In addition to this the image below is a schematic representation of the concept of the three proposed models. (Fig. 3)

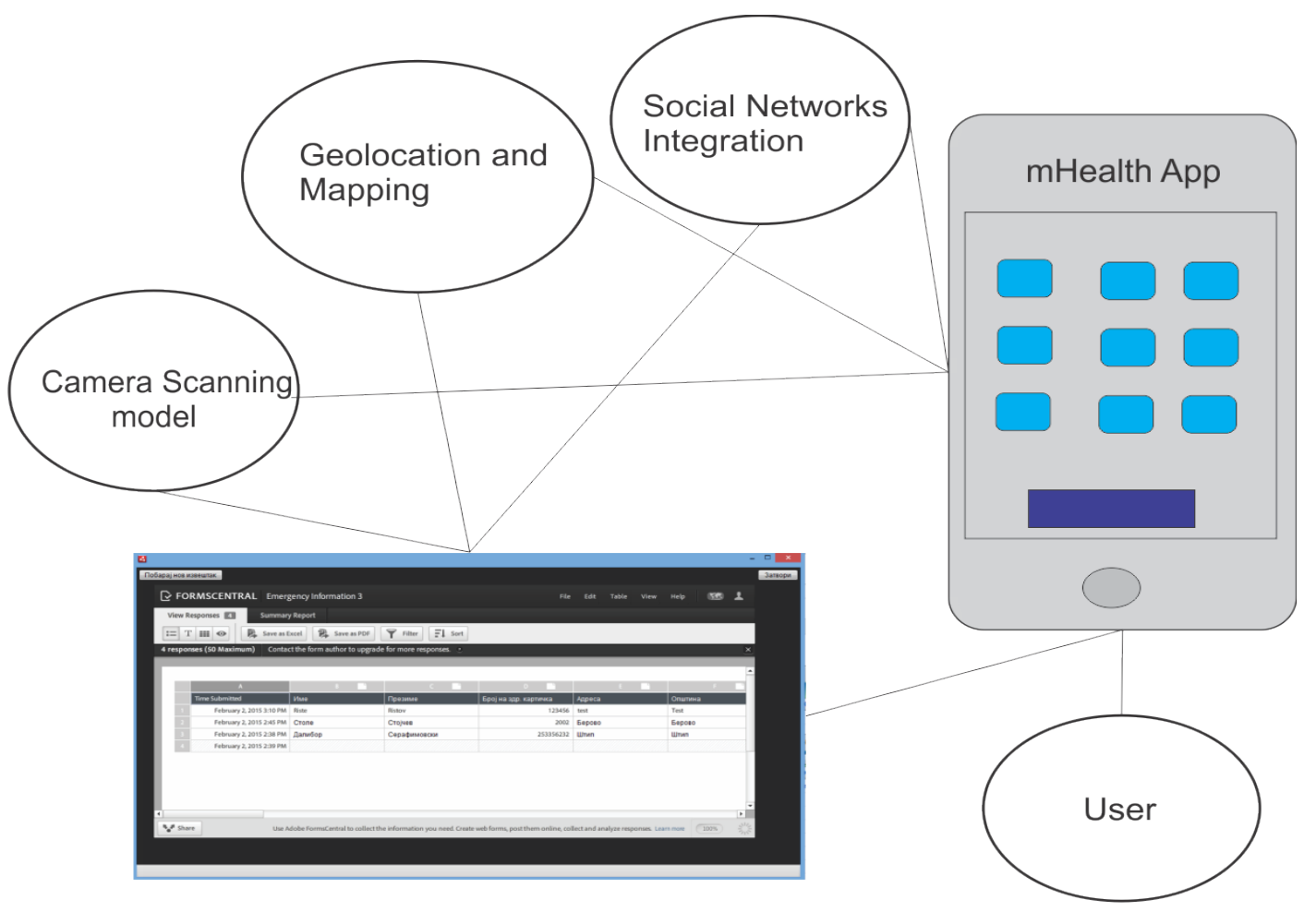

Fig.3 Schematic representation of the concept of the proposed models 


\section{CONCLUSION}

Many experiments and surveys were conducted as part of this research in the laboratory and in the field in order to test the functionality of the cross-platform mobile applications in the process of transmission and storage of data in medical purposes. We proposed three models practically tested in the laboratory and in the field. All three models provide some informal data that form the basis for further research. It is necessary in the future to continue developing using cross-platform technologies. These technologies are showing huge development potential in medical purposes. In the future a growing number of medical professionals and software developers will work on developing systems for data transmission in medical purposes using smart mobile devices. Smart watches are included in this story at the right moment. Our following research will be directed towards to apply all the functionalities of already established mobile applications mentioned in the text above to the new generation of smart watches. This will lead in the future to increased efficiency, increased speed and reliability of data transmission and dramatically reduced costs.

\section{REFERENCES}

[1]. Rodrigues, Joel J.P.C.: Mobile Networks and Cloud Computing Convergence for Progressive Services and Applications, IGI Global, pp 40-48, 2013

[2]. J.J. Berman: Methods in Medical Informatics, Fundamentals of Healthcare Programming in Perl, Python, and Ruby, CRC Press, Taylor and Francis Group LLC, pp 48-60, 2011

[3]. Michael J. Williams: Facebook Graph API Development with Flash, Packt Publishing, pp 75-90, 2010

[4]. Yakov F. Viktor R. Anatole T.: Enterprise Development with FLEX, Adobe Developers Library, pp 55-90, 2010

[5]. P. Bertelsen, C. Nohr, L. Botin: Techno-Anthropology in Health Informatics: Methodologies for Improving Human-Technology Relations, IOS Press, pp 120-160, 2015

[6]. J. Donner, P. Mechael: mHealth in Practice: Mobile Technology for Health Promotion in the Developing World, Bloomsbury, pp 62-90, 2013

[7]. R. Carsten: Smart Healthcare Applications and Services: Developments and Practices, IGI Global, pp 220-240, 2010

[8]. Joseph T.: Developments in Healthcare Information Systems and Technologies: Models and Methods, IGI Global, pp 95-116, 2010

[9]. Renata S.: Health Communication: From Theory to Practice, John Wiley \& Sons, pp 324360,2011

[10]. The International Conference on Health Informatics: ICHI 2013, Vilamoura, Portugal on 7-9 November, Vol. 42, Springer International Publishing, pp 240-265, 2013 